\title{
Syntactic Perfective Aspect
}

\author{
Author: Assistant Lecturer kamal khazal \\ College: imam Al-kadhum university college \\ Email: kamal khazal@al kadhum-col.edu.iq
}

Mobile :009647705573147

\begin{abstract}
The purpose of this research is to examine the perfective aspect of linguistics, how it is used, and its importance in language. This research provided a more detailed explanation of the perfective aspect individually to understand it more comprehensively. This examination of the perfective aspect provided the basis on which the analysis occurred. This research analyzed the perfective aspect through its use in language. It is hoped that this explanation will provide greater inside into the identification of the perfective aspect and the usage of the perfective aspect in various languages as well as how it can be understood in English.
\end{abstract}

Keywords: : perfective, tense, syntactic, experiential, continuative ,aspect.

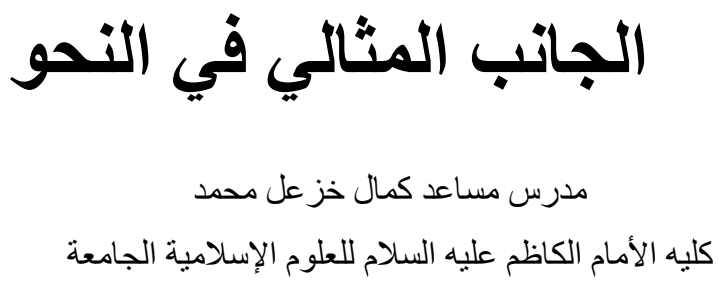

خلاصة البحث

الغرض من هذا البحث هو در اسة الجانب المثالي للسانيات ، وكيفية استخدامها ، و أهميتها في اللغة. قدم هذا البحث شرحًا أكثر تقصيلًا للجانب المثالي بشكل فردي لفهمه بشكل أكثر شمولًا. سلط البحث الضوء على الجانب المثالي الذي من خلاله استند إلبه التحليل. حلل هذا البحث الجانب المثالي من خلال استخدامه في اللغة. من المأمل أن يوضح البحث الجانب العميق لهوية الجانب المثالي واستخدام الجانب المثالي في لغات مختلفة وكذلك كيف يمكن فهمه باللغة الإنجليزية

الكلمات المفتاحية: التام، الزمن، النحوية، التجريبية، المستمر، صيغة الفعل.

\section{Introduction}

An explanation of the perfective aspect, particularly with the foundation of knowledge on aspect and tense, reveals the significant complexities in linguistics and syntax. An analysis of the identification of the perfective aspect indicates that the ability to identify the perfective aspect may depend on the language in which the identification takes place. For example, it may be difficult to identify the perfective aspect in English 
because of the incompatibility of the aspect with the progressive as well as mixed markers, such as the use of -ing in English. However, in other languages, the perfective aspect is used widely, making it much more easily identifiable in an examination of syntax.

The same is true in the use of the perfective aspect in language. The perfective aspect is used significantly more frequently in some languages, but rarely occurs, if at all, in others. In some languages, there are complications when using the perfective aspect. For example, in English, perfective and progressive cannot grammatically coexist. While there may be ways to reword or work around this complication, it does exist, and can be a barrier to understanding the language, particularly if an individual has a native language in which this is not a barrier.

Nonetheless, identifying the perfective aspect may be difficult depending on the language in which the identification is taking place. For example, English does not typically have the perfective aspect. Therefore, identifying it in English may be more difficult. Conversely, languages in which the perfective aspect is used widely may be as easy to identify as past tense in English. This research explores the identification of the perfective aspect of language so that individuals may be able to identify the perfective aspect when they encounter it in everyday usage.

Within research, achievement and accomplishment are frequently examined together due to their similarities. However, it is the element of duration versus non-duration that separates the two within linguistics. To that end, Caudal (1999) proposed that this perspective should be changed to better understand the two. According to Caudal (1999, p . 9)
[...T]he so-called punctuality of events should be reduced to the notion of atomicity. It has been shown that (non)atomicity is at least partly a compositional semantic category, rather than a purely pragmatic one, and that it is directly related to incrementality in many cases, though not in all cases.

It is this similarity, along with others in syntax and, in particular, perfective aspect, that can be problematic for individuals seeking to identify the usage of the perfective aspect in language. This is particularly true in English because of the conflicting markers provided in the language. For example, the word already in English is separate from the perfective aspect (Vander Klok\& Matthewson, 2015). According to the authors, there are five criteria that separate already from the perfect aspect: “(i) duality of already, (ii) earliness conversational implicature, (iii) inchoativity effects with stative predicates, (iv) compatibility with past temporal adverbials, and (v) Extended Now effects" (Vander Klok\& Matthewson, 2015, p. 201). Though this argument separates already from the perfective aspect, it is frequently included as marker for the perfective aspect in language usage, thereby causing conflict in interpretations when studying English linguistics.

This is due, at least in part, to the role progressives play in the perfective aspect. According to Szabó (2004,p. 54 ):

Semanticists working on aspect have long sought to provide a semantic analysis of perfective sentences in terms of their progressive correlates. [...] The analysis suggests that a perfective telic sentence $y$ is true just in case its progressive correlate $\operatorname{Prog}[\mathrm{y}]$ is true of some event, its target 
مجلة لارك للفلسفة واللسانيات و العلوم الاجتماعية العدد (36) الاصدار 1- 01 - 2020 (بحوث اللغة الإنكليزية)

correlate $\mathrm{Tel}[\mathrm{y}]$ is true of some state, the

event causes the state, and any event

between them in the causal chain is such that $\operatorname{Prog}[\mathrm{y}]$ is true of it.

One of the advantages of this analysis is that "it accounts for inferences that plausibly belong to semantics" (Szabó, 2004, p. 54). The approach also applies to usage in that an analysis of the future and past tenses requires an understanding of present tense since the culmination of an event is understood by virtue of the process that led to it (Szabó, 2004).

It is also important to understand the differences between written and verbal language. In many languages, verbal categories are different from written categories (Wallace, 1982). Part of the reason for this is that verbal language can include inflections that may not be as easily included in written language. In verbal language, tone and inflection can be used as clues to the intention of the utterance. However, in written language, the reader only has the textual clues to determine meaning. Inflection, at least in English, is typically not included. Therefore, it becomes even more vital to understand the intricacies of grammar and syntax in order to understand the language and identify the perfective aspect.

One key component in the identification of the perfective aspect usage is to understand the formula required for it to be present. As a reminder, the perfective aspect of a verb is the use of a compound verb. It requires:

A form of has + past participle

For example:

(1) (a) Emily has sat in the chair.
While there are variations of this form, and different languages apply it differently, the basic form remains the same. Therefore, in order to identify it, one needs only to know and understand the formula and be able to recognize it in various forms. The following examples utilize the perfect aspect in the three tenses:

(b) Emily has sat in the chair. PERFECT PRESENT

(c) Emily had sat in the chair. PERFECT PAST

(d) Emily will havesat in the chair. PERFECT FUTURE

In (1)(b), the sentence is perfect present because of the combination of the form of has and the pasttense verb sat. In (1)(c), the use of had rather than has makes the sentence perfect past rather than perfect present. Finally, in (1)(d), the use of will have combines the future (will) with the form of has (have) along with the past participle (sat) to create the perfect future sentence. Though these sentences each uses a different tense, all three employ the perfective aspect. Understanding the formula to create the perfective aspect facilitates the identification of the perfective aspect in language.

\subsection{Perfective Aspect}

It is important to differentiate between perfect tense and perfective aspect. Perfect tense focuses on tense, such as perfect present tense, which Emily will have sat in the chair. Perfective aspect, on the other hand, describes an action as a unit without internal composition. Most often, perfective aspect is viewed in non-English 
مجلة لارك للفلسفة واللسانيات و العلوم الاجتماعية العدد (36) الاصدار 1- 01 - 2020 (بحوث اللغة الإنكليزية)

languages because, in English, there is no simple perfective or imperfective aspect.

It should be noted that one challenge of this perspective is the inability for it to be applied effectively to English, which provides an area in which further research would be beneficial to the study of linguistics. According to Pancheva (2003, p. 294-295):

Another argument comes from the observation that there are distinctions of grammatical aspect as well, between the Experiential and the Resultative perfects. The Resultative perfect does not allow the progressive in English, whereas both the Universal and the Experiential do.

a. I have been drinking coffee at least since 3 o' clock.

$\mathrm{U}$

b. I have been drinking coffee on many occasions before.

\section{EXP}

c. *I have been drinking this cup of coffee right now.

RES

Similarly, the English language does not allow for past-tense adverbials in perfect present. For example:

(3) (a) Emily has sat in the chair yesterday.

(b) Emily has sat in the chair today.

While (3) (a) is grammatically correct in order to serve its purpose, it does not really make sense in English. The same is true for (3) (b). Though there is the implication that the sitting occurred in the past in (3) (b), even if it occurred today, the use of sat with today does not work in English grammar. Read aloud, these examples are jarring to the ear. Instead, an English speaker would say:

(c) Emily sat in the chair yesterday/today.

This satisfies the past tense verb sat, but is not in the perfect present tense due to the exclusion of a form of the verb have. It should be noted that there are ways around this grammatical problem in English. For example, the information could be provided in separate sentences. However, does not serve the purposes of the discussion.

Another possible way to work around for this problem is to alter the temporal clue. If the temporal clue were indefinite it could be grammatically acceptable. For example:

(d) Emily has sat in the chair [on a Saturday].

In $(3)(d)$, the inclusion of the indefinite temporal reference of a Saturday rather than a specific Saturday changes the construction of the sentence, which makes it acceptable, even if odd (Portner, 2003).

Despite these challenges, the perfective aspect is considered uncontroversial (Singh, 1998; DeLancey, 1982). According to Singh (1998, p. 172), “[...I]n many languages the perfective can be used for at least the non-stative situation types, namely achievements, activities, and accomplishments. Sometimes it can be used with states as well, as in the case in English" The perfective aspect is more natural for use with achievement verbs in comparison to the 
imperfective and refers to a state change (Singh, 1998). In the context of activities, the perfective aspect addresses the arbitrary endpoint (Singh, 1998). In accomplishments, the perfective aspect is used to emphasize the natural endpoint of the situation (Singh, 1998). While this perspective is effective to improve understanding of the perfective aspect, it is not true in all languages. According to Singh (1998, p. 173):

Specifically, in several languages, notably Hindi, Chinese, and Japanese, the perfective form may be used with verbs that usually denote an accomplishment to mean that the described situation has reached an endpoint, but not necessarily the natural one that would signify the accomplishment.

Singh (1998) refers to this as the neutral perfective viewpoint because it presents an event as a whole but does not require that the event is completed at the time of utterance.

This conclusion arises not only out of the need in certain languages, but also because of the overlapping characteristics in some classifications. According to Singh (1998, p. 173):

Accomplishments have features of both activities and achievements: they call for extended action and also have a natural endpoint. [...] In a language such as English, the use of a simple verb (SV) by default indicates that the natural endpoint is reached, but an additional description is required to state that the action was stopped at an arbitrary point.

In other languages, such as Hindi, compound verbs are used for natural endpoints while simple verbs are used for arbitrary endpoints (Singh, 1998). There are three types of perfective aspect and tense addressed in this research: experiential, continuative, and resultative. According to Portner (2003, p. 459):

Perhaps the one thing that current analyses of the perfect agree upon is that a present perfect sentence like (3) indicates some type of connection between a past event, of Mary eating breakfast, and the time indicated by the sentence's tense, the speech time:

(4) Mary has eaten breakfast already.

Within this context, the three classifications of the perfective can be examined and understood. This section explores these three classifications of the perfective aspect.

\subsubsection{Experiential Perfective Aspect}

In simplest terms, the experiential perfect reaches into the past without taking place in the past. According to RoumyanaPancheva (2003, p.277), "The EXPERIENTIAL perfect [...] asserts that the underlying eventuality holds at a proper subset of an interval, extending back from the utterance time" That is, the event being referred to both began and concluded prior to the utterance. Since this discussion is focusing on the perfect, the event must also have concluded prior to the utterance. For example:

(5) (a) Emily has been in the chair [before].

(6) In (4)(a), the emphasis in temporal markers suggests that the event occurred in the past. The same can be 
مجلة لارك للفلسفة واللسانيات و العلوم الاجتماعية العدد (36) الاصدار 1- 01 - 2020 (بحوث اللغة الإنكليزية)

said when returning to the example of

Mary and her breakfast:

(b) Mary has eaten breakfast [before].

In this sentence, perfect present is used, but there is the suggestion of a component of the event as having taken place in the past. However, there is no indication that it is currently occurring. As a result, the experiential perfect aspect is telic, suggesting an endpoint, even if it is not definitive or explicitly stated. That is, Mary ate breakfast (before now), but she is not eating breakfast (now). This places this example securely in the past.

In addition, experiential perfect aspect "is accompanied by the usual adverbials (ever, never), and the perfect of persistent situation by the temporal adverbs for duration (a long time, all night, ever since)" (Novakov, 2009, p. 282). Within this context, (4)(b) could be expressed as:

(c) Mary has eaten breakfast all morning.

(d) Mary has been eating breakfast all morning.

It should be noted that, in the case of (4)(b), it may be that Mary is still eating breakfast. The context of the sentence as written could be interpreted as continuous rather than as having an endpoint. More commonly, the English construction of this expression would be:

(e) Mary was eating breakfast all morning.

However, without the form of have as well as the past participle, this expression does not qualify as the perfective aspect.

\subsubsection{Continuative Perfective Aspect.}

The continuative perfect aspect, referred to as universal by Pancheva (2003), suggests an ongoing timeframe. According to Pancheva (2003, p.277), "The UNIVERSAL perfect [...] asserts that the underlying eventuality holds throughout an interval, delimited by the time of utterance and a certain time in the past" For example:

(4) (f) Since 4:00 p.m., Emily has sat in the chair.

Or, once again returning to Mary:

(4) (g) Mary has been eating breakfast since 7:00 a.m.

In (4)(f), the addition of time (Since 4:00 p.m.) provides a starting point of the event with the implication that it is continuing at the time that the sentence occurs, unlike in (4)(a) and (4)(b), in which the event is no longer occurring. This makes the continuative perfective aspect atelic, since it does not have an endpoint. The same is true in (4)(d), though the inclusion of has been along with eating adds a layer of complexity.

In English, only the progressive and stative verbs can be used in the continuative perfective aspect (Pancheva, 2003; Dowty\& David, 1972). In addition, in languages with imperfective/perfective distinctions, "the availability of the [Continuative] reading depends on the availability of nonperfective participles. Greek, for instance, obligatorily marks perfect participles as perfective, and as a result the [Continuative] perfect is not possible in this language" (Pancheva, 2003, p. 278). This takes on a similar role to the progressive in English (Pancheva, 2003).

\subsubsection{Resultative Perfective Aspect.}


The resultative perfect is similar to the experiential perfective aspect. According to Pancheva (2003, p. 277), "The RESULTATIVE perfective makes the same assertion as the Experiential perfect, with the added meaning that the result of the underlying eventuality holds at the utterance time". For example:

(4) (h) Emily has [just] sat in the chair.

Or, when once again returning to the example of Mary:

(4) (i) Mary has [just] eaten breakfast.

In this sentence, the implication is that, while Emily sat in the chair previously, she is still sitting in the chair. As with the continuative perfect examples, the resultative perfect is also atelic, having no endpoint. It is in this scenario that the sentence may be more likely to be worded as in (4)(d) since there is a need for the eventuality to be true at the time of utterance. However, as was previously stated, the use of eating rather than the past-tense eaten precludes the construction from qualifying as perfective.

Like the continuative perfective aspect, the resultative perfective aspect has restrictions. According to Pancheva (2003, p. 278), "For this reading to obtain, the result state of the underlying eventuality must hold at the reference time" . For example, in (4)(e), for the statement to qualify as resultative perfective, Emily must be sitting in the chair at the time of utterance. However, if Emily is not sitting in the chair at the time, the statement would instead be experiential.

It should be noted that there is some dispute among grammarians as to whether or not resultative perfective is telic or atelic. However, the necessity of telic or atelic is more directly related to the classification of the verb (accomplishment, achievement, state, or activity). According to Pancheva (2003, p. 278-279).

The telos is the 'turning point' at which telic eventualities transition into the result state. With the reaching of the telos, an achievement such as lose my glasses causes a state of the glasses being lost, and an accomplishment such as build a sandcastle quite clearly results in a state of the existence of a castle. There is no analogous inherent result state for an activity such as run or build sandcastles. With this in mind, the interpretation of some sentences cannot be resultative. For example:

(7) (a) I have run.

In (10)(a), the activity, which does not necessarily have an endpoint, does not evoke either the existence of running or a state of running in the same way build a sandcastle or lose my glasses do. Therefore, I have run cannot be interpreted as resultative. A resultative interpretation relies significantly on aspect for an understanding of meaning and intention (Pancheva, 2003).

\subsection{The Analysis of Perfective Aspect Through Its Use in Language.}

Throughout the existing body of knowledge on the perfective aspect, there is a great deal of emphasis on the application of knowledge of the perfective aspect to understand other languages. In 
مجلة لارك للفلسفة واللسانيات و العلوم الاجتماعية العدد (36) الاصدار 1- 01 - 2020 (بحوث اللغة الإنكليزية)

some cases, this is used to understand the perfective aspect better since the simple perfective aspect does not exist in English. In other cases, this is used to understand other languages, such as in the case of individuals learning another language that uses the perfective aspect, such as a native English speaker learning another language. While the existing body of knowledge is beneficial, much of the research is more theoretical than practical. This research focuses on syntax and grammar as an academic practice, using examples to illustrate. However, this may leave a gap in knowledge in which analysis does not adequately help individuals understand the practical application of the perfective aspect. Instead, it is explored from the perspective of academia, and even the so-called practical applications focus on learning a language.

The foundation of information about the perfective aspect in this research has included examples, it has remained predominantly theoretical, as well. However, it may be that many individuals understand the perfective aspect in this context, but are unable to identify it in practical use in order to more effectively understand language and its use. In addition, though individuals may understand the perfective aspect, they may not have a strong understanding of how it is used in practical language. By focusing on the identification of the perfective aspect and how it is used in language, the understanding of the perfective aspect in the theoretical context can be deepened, which may help individuals better understand languages that are new to them. Since the perfective aspect cannot really be found in English, this section will examine the identification and usage of the perfective aspect as it applies in non-English languages.
The next component of analysis is in the usage of perfective aspect in language. It is in the usage that an individual may learn more effectively how to identify perfect aspect usage, as well. After all, if an individual, such as a language learner, understands how to use perfective aspect, he or she may be more likely to be able to identify it when it is presented in language.

It is important to understand that the usage of the perfective aspect varies based on the language in which it is spoken. Therefore, an analysis of the use of the perfective aspect must be undertaken through an analysis of multiple languages. According to Heath (1981, p. 101):

$[\ldots W]$ hereas in many languages (e.g., Russian) aspect is neutralized in favor of the durative (continuous, imperfective) form rather than the punctual (perfective) form, and this pattern also occurs in Nunggubuyu NC prefixes and past tense verbs, we also find examples of the opposite. In Mara, it is the NONDUR steminitial that is generalized in negative (and imperative positive) forms.

The use of the perfective aspect may be complicated for those learning a new language, particularly if one of the two languages does not use the perfective aspect. According to Sugaya and Shirai ,2007), the syntax and grammar of a learner's native language has an impact on the way they learn a second language. According to the researchers, "Our findings suggest that the effect of L1 might contribute to the formation of acquisition patterns predicted by the aspect hypothesis but that this acquisition might be mediated by task type and L2 proficiency" (Sugaya\&Shirai, 2007, p. 29-30). However, it should be noted that the authors

\subsubsection{Perfective Aspect Usage.}


مجلة لارك للفلسفة واللسانيات و العلوم الاجتماعية العدد (36) الاصدار 1- 01 - 2020 (بحوث اللغة الإنكليزية)

indicate that research yields mixed results rather than definitive results (Sugaya\&Shirai, 2007).

It may be that this complication arises because of the language diversity in the world. However, some grammarians argue that the reverse is true: that diversity in the world's languages comes from the process by which grammar develops. This can be seen, for example, in the development of the perfective aspect in Indo-Aryan languages (Hook, 1991). According to Hook (1991, p. 63-64):

Russian or Czech-speaking Ideologists commonly identify Hindi-Urdu [compound verbs] as being perfectives. [...] For instance, in Russian it has been observed that clauses which are dependent on expressions of fear and anxiety show a preference for perfective forms of the verb which borders on being categorical:

(7) mat' bojalas' kak-by
eёsyn ne zabolel
mother feared lest
her son NEG took-sick-PFV
'The mother was afraid
that her son might get sick.'

There is similar (although not quite so univocal) preference for perfective forms in clauses dependent on expressions that mean 'until' [...]. These asymmetries in the distribution of aspectual forms in Russian are closely paralleled in Hindi-Urdu [...]. Applying these same tests to Marathi we find that its [compound verb/simple verb] opposition does not regularly express either relative tense or perfectively.

This supports the difference in functions of compound verb/simple verb opposition in these two languages (Hook, 1991). The difference in function between compound verbs and simple verbs is frequently seen in English, such as in is sitting (compound verb) and sat (simple verb) in the primary example of Emily and her chair. Often, the difference is to clarify (present tense versus past tense) or to satisfy a requirement of usage (perfect versus imperfect). In either case, the verb function contributes to the identification and usage of either perfective or imperfective aspect in the construction of the utterance.

Another area in which this can be seen is in the comparison of spoken and signed languages (Anderson, 1982b). For example, in American Sign Language, temporal clues exist just as they do in written and spoken English. This is illustrated in Figure 4, which shows a textual representation of perseverative reduplication rhythms in American Sign Language and in English.

\begin{tabular}{|c|c|c|}
\hline & ASL type & English translation-equivalents \\
\hline (a) & $\begin{array}{l}\text { Return to } \rightarrow 1 \\
\text { starting } \rightarrow 1 \\
\text { point } \rightarrow\end{array}$ & $\begin{array}{l}\text { 'to look at it again, and again, and again' } \\
\text { 'he worked, and worked, and worked (but } \\
\text { still it wasn't finished)' }\end{array}$ \\
\hline (b) & $\begin{array}{l}\text { Successive } \rightarrow 1 \\
\text { advances } \rightarrow 1 \\
\\
\rightarrow\end{array}$ & $\begin{array}{l}\text { 'to fly on, and on, and on' } \\
\text { 'to sail on, and on, and on' }\end{array}$ \\
\hline
\end{tabular}

Figure 1 (Anderson, 1982b, p. 95)

In English, words can be used, particularly repetitively, to convey a sequence, such as chair after chair after chair. The same is true in American Sign Language. However, when conveying a large number of an item existing simultaneously, such as chairs and chairs and chairs and chairs in English, a parallel in American Sign Language does not exist (Anderson, 1982b). However, in English, the repetitive use of the word 
مجلة لارك للفلسفة واللسانيات و العلوم الاجتماعية العدد (36) الاصدار 1- 01 - 2020 (بحوث اللغة الإنكليزية)

(chairs and chairs and chairs and chairs) is not typically used to convey a great number of chairs. The same is true in American Sign Language. Therefore, while there is a difference in the ability in the two languages for this usage, the practical application of language is the same in both.

It is important to note, as well, that American Sign Language, by its nature is highly reliant on inflection, which is conveyed through the way gestures are made as well as facial expressions. Therefore, while there are "limitations" in the grammatical aspects of American Sign Language in comparison to written and spoken languages, the frequent use of inflection in American Sign Language helps accommodate this to ensure understanding.

Research into world languages, then, provides a foundation of understanding about their diversity as well as identifying some commonalities, particularly in the grammaticization of language and how individual languages developed.According to Bybee and Dahl (1989, p. 96-7):

$[\ldots T]$ he observed diversity in tense and aspect in the languages of the world is due to the particular properties of the grammaticization process, such as the following:

i. the independence of the development of each gram-type allows considerable variation as to which of the gram-types are interacting in a language at any given time;

ii. moreover, at any one stage a language may have grams that are close to one another semantically; e.g. it is not uncommon for a language to have more than one gram expressing the notions associated with future;

iii. languages may vary with respect to the possible combinations of tense and aspect grams; that is, future perfect or past progressive may or may not be possible combinations;

iv. languages may vary in the extent to which other less common gramtypes such as habitual, evidential, or degrees of remoteness interact with the major grams;

$v$. in the case of aspect, languages may have derivationally expressed meanings, as in the Slavic languages, which interact with the inflectional tenses;

vi. differences may be found among grams compared cross-lingually, (a) according to the original lexical source of the gram, since certain nuances of meaning may be retained for long periods of time, and (b) according to where the gram stands on its particular path of grammaticization.

This suggests that understanding the grammaticization process can help individuals understand language and how it developed, which can then help individuals find commonalities in languages by tracing the process backwards through its development. For language learners, this understanding can help draw parallels between the native language and the language being learned, making the language acquisition process easier and more effective (Robinson,1990).

Another complication in the use of the perfective aspect occurs in English with motion verbs. 
مجلة لارك للفلسفة واللسانيات و العلوم الاجتماعية العدد (36) الاصدار 1- 01 - 2020 (بحوث اللغة الإنكليزية)

According to DeLancey (1982 , p. 169 ), "Most motion verbs are not oriented. In English, verbs like return, cross, leave, enter, approach, arrive can be used without any clear specification of viewpoint. Many languages prefer or require such specification" One way this is accomplished is through the use of auxiliary verbs. DeLancey (1982, p. 169) provides an example of this:

In Thai, for example, a non-oriented verb such as klap "return" is specified for viewpoint by the verbs pay "go" or maa "come":

8) Somsakklap pay leew

"Somsak has gone back."

9) Somsakklapmaaleew

"Somsak has come back."

Not all languages have this differentiation, however. In Jinghpaw and many Tibeto-Burman languages, as well as in French, oriented motion verbs do not exist (DeLancey, 1982). When sentences are translated from these languages into a language in which orientation is required, they must often include auxiliary verbs. For example, consider: "MaNaw gat de' sawanu'ai" which translates to "MaNaw has gone to market" or "MaNaw is coming/will go to market" (DeLancey, 1982, p. 169). Since the verbs saand $w a$ are motion verbs with no orientation, translating this phrase into English requires the addition of auxiliary verbs to more accurately convey meaning.

It should also be noted that, even within one language, there may be differences in grammar and syntax between written and spoken languages. Wallace (1982) draws four specific conclusions in his examination of tense-aspect between semantics and pragmatics. According to Wallace (1982, p. 216):

1. Verbal categories blend and associate, and indeed they tend to blend and associate in certain ways rather than in others (e.g. imperfective aspectuality and non-eventive modality).

2. Verbal categories and nominal categories are apt to correlate in specific ways (e.g. "individuated" entities with perfective, "nonindividuated" entities with imperfective).

3. Verbal categories, as well as nominal categories, play important roles in foregrounding and backgrounding information in discourse (e.g. perfective foreground, imperfective background).

4. A fundamental organizing principle behind this apparent diversity of facts is the figure-ground distinction.

Wallace (1982) concedes that the figure-ground distinction does not explain all things. However, his assertion of the verbal categories as different from written is significant. Wallace (1982) states that in verbal categories, imperfective aspectuality and non-eventive modality frequently occur together. This is because the nature of non-eventive modality is to provide context and background, which can heighten or emphasize the events taking place (Wallace, 1982, p. 209). According to Wallace (1982):

At least under normal circumstances, one would expect people to be more interested in what is factual or real. What someone asserts as actually happening or having happened is likely to be closer to the center of attention - the foreground - than 
مجلة لارك للفلسفة واللسانيات و العلوم الاجتماعية العدد (36) الاصدار 1- 01 - 2020 (بحوث اللغة الإنكليزية)

what did not happen, or might happen, or could happen, or should happen, or perhaps happened, or what someone wants to happen.

With this distinction, then, it can be understood why, at least in verbal categories, that imperfective aspectuality and non-eventive modality occur together.

\subsection{Conclusion}

The perfective aspect describes an action as a unit without internal composition. This research is focused on an explanation of the experiential, continuative, and resultative perfective aspects. The experiential perfective aspect reaches into the past, but does not signify whether the event is occurring at the time of utterance. The continuative perfective aspect is, as its name suggests, ongoing at the time of utterance. Finally, the resultative perfective aspect suggests the past, but adds the component that the event holds true at the time of utterance. The explanations and examples in this research provide an understanding of the perfective aspect as well as various ways it is used in language (experiential, continuative, and resultative).

\section{References}

Anderson, L. (1982b). Universals of aspect and parts of speech: Parallels between signed and spoken languages. In P. J. Hopper (Ed.) Tense-Aspect between Semantics \& Pragmatics, 91-114. Philadelphia, PA: John Benjamins Publishing Company.

Bybee, J. L. \& Dahl, Ö. (1989). The creation of tense and aspect systems in the languages of the world. Studies in Language, 13(1), 51-103.

Caudal, P. (1999). Achievements vs. accomplishments: A computational treatment of atomicity, incrementality, and perhaps of event structure. Conference
TALN,1-10. Retrieved

from https://www.atala.org/doc/actes_taln/AC_0 127.pdf

DeLancey, S. (1982). Aspect, transivity, and viewpoint. In P. J. Hopper (Ed.) TenseAspect between Semantics \& Pragmatics, 167-184. Philadelphia, PA: John Benjamins Publishing Company.

Dowty, D. R. (1977). Toward a semantic analysis of verb aspect and the English 'imperfective' progressive. Linguistics and Philosophy, 1(1), 45-77. doi: 10.1007/BF00351936

Heath, J. (1981). Aspectual "skewing" in two Australian languages: Mara, Nunggubuyu. In P. J. Tedeschi\& A. Zaenen (Eds.) Syntax and Semantics, 91-102. New York, NY: Academic Press.

Hook, P. E. (1991). The emergence of perfective aspect in Indo-Aryan languages. In E. C. Traugott\& B. Heine (Eds.) Approaches to Grammaticalization: Volume II, 59-89. Philadelphia, PA: John Benjamins Publishing Company.

Novakov, P. (2009). Semantic features of verbs and types of present perfect in English. Selected Papers from the 18 $8^{\text {th }}$ ISTAL, 281-8. Retrieved from http://www.enl.auth.gr/symposium18/paper s/29_Novakov.pdf

Pancheva, R. (2003). The aspectual makeup of perfect participles and the interpretations of the perfect. Retrieved from http://wwwbcf.usc.edu/ pancheva/Pancheva(2003).pdf

Portner, P. (2003). The (temporal) semantics and (modal) pragmatics of the perfect. Linguistics and Philosophy, 26, 459-510. 
Robinson, R. E. (1990). The primacy of aspect:

Aspectual marketing in English interlanguage. Studies in Second Language Acquisition, 12(3), 315-30. doi: 10.1017/S0272263100009190

Singh, M. (1998). On the semantics of the perfective aspect. Natural Language Semantics, 6, 171-99.

Sugaya, N. \&Shirai, Y. (2007). The acquisition of progressive and resultative meanings of the imperfective aspect marker by L2 learners of Japanese: Transfer, universals, or multiple factors? SSLA, 29, 1-38. doi: $10.1017 / \mathrm{S} 0272263107070015$

Szabó, Z. G. (2004). On the progressive and the perfective. NOÛS, 38(1), 29-59.

Wallace, S. (1982). Figure and ground: The interrelationships of linguistic categories. In P. J. Hopper (Ed.) Tense-Aspect between Semantics \& Pragmatics, 201-226. Philadelphia, PA: John Benjamins Publishing Company.

Vander Klok, J. \&Matthewson, L. (2015). Distinguishing already from perfect aspect: A case study of Javanese wis.Oceanic Linguistics, 54(1), 172-205. 